\title{
MECANISMOS DE PARTICIPAÇÃO POLÍTICA, FISCALIZAÇÃO E CONTROLE: O PAPEL DAS OUVIDORIAS E DA LEI DE ACESSO À INFORMAÇÃO COMO INSTRUMENTOS DE COMUNICAÇÃO GOVERNAMENTAL, TRANSPARÊNCIA E PUBLICIDADE
}

\author{
Alan Santos de Oliveira ${ }^{1}$ \\ Ana Claudia de Almeida Pfaffenseller ${ }^{2}$ \\ Arnaldo Podestá Junior ${ }^{3}$
}

\begin{abstract}
Resumo
A pesquisa traz uma análise acerca da importância dos dispositivos democráticos de controle sobre os atos praticados pelo Estado e seus agentes, tendo como premissa o ordenamento jurídico brasileiro, sob a égide da transparência e acesso à informação. Para isso, fez-se uma discussão inicial dos conceitos de accountability, transparência e publicidade, procurando, em seguida, identificar suas dimensões essenciais e resultantes na sociedade contemporânea, relacionando-as com as Ouvidorias e a Lei de Acesso à Informação - LAl. Para melhor compreensão da análise proposta, realizou-se uma pesquisa bibliográfica e documental com base em materiais já publicados, tais como livros, artigos, teses, dissertações e, também, documentos de domínio público, como coletâneas, relatórios, leis, decretos, declarações e pactos. Baseando-se nos princípios da transparência, da fiscalização e da cidadania, a pesquisa possibilitou constatar diferenças conceituais entre transparência e publicidade, sem, contudo, inviabilizar o poder da participação.
\end{abstract}

Palavras-chave: Accountability. Transparência. Participação. Acesso à Informação. Ouvidoria.

DOI:10.37814/2594-5068.2019v2.p55-69

1 Ouvidor e Docente do Centro Universitário de Patos de Minas - UNIPAM. Possui Mestrado em Educação pela Universidade de Uberaba - UNIUBE (2009), MBA em Comunicação Empresarial (2004), Bacharelado em Secretariado Executivo pela União Pioneira de Integração Social - UPIS (2002) e Bacharelado em Ciência Política pelo Centro Universitário Internacional - UNITER (2018). É avaliador de Cursos de Graduação/Instituições de Ensino Superior - IES do Instituto Nacional de Estudos e Pesquisas Educacionais Anísio Teixeira - INEP/Ministério da Educação MEC. É parecerista da Editora Intersaberes. É Presidente do Fórum Nacional de Ouvidores Universitários - FNOU / Gestão 2016-2018.

2 Ouvidora-Geral da Universidade de Santa Cruz do Sul - UNISC, onde também atua como Docente nos cursos do Centro de Educação Profissional da UNISC. Possui Pós-graduação Stricto Sensu Mestrado em Letras pela UNISC (2016), Pós-graduação Lato Sensu em Gestão Universitária pela UNISC (2013), Graduação em Comunicação Social - Jornalismo pela UNISC (2006) e é Graduanda em Letras pela Universidade Federal do Pampa - UNIPAMPA. É Vice-presidente da Região Sul do Fórum Nacional de Ouvidores Universitários - FNOU / Gestão 2016-2018.

3 Ouvidor-Geral da Universidade Federal de Santa Catarina - UFSC desde 2004. Possui Mestrado em Engenharia de Produção - Área de Qualidade e Produtividade pela UFSC, Especialização em Recursos Humanos pela UFSC e Graduação em Administração pela UFSC. É Secretário-Geral do Fórum Nacional de Ouvidores Universitários FNOU / Gestão 2016-2018. 


\begin{abstract}
The research developed an analysis about the importance of democratic control mechanisms over the acts practiced by the State, based on the Brazilian legal system, under the support of transparency and access to information. For this, an initial discussion was held about the concepts of accountability, transparency and publicity, and then sought to identify their essential and resulting dimensions in contemporary society, relating them to the Ombudsman and the Brazilian Law of Access to Information. To better understand the proposal, a bibliographical and documentary research was carried out, based on published materials: books, articles, theses, dissertations and also public domain documents, collections, reports, laws, decrees, declarations and covenants. Based on the principles of transparency, supervision and citizenship, the research made it possible to verify conceptual differences between transparency and publicity, without, however, making the participation power unfeasible.
\end{abstract}

Keywords: Accountability. Transparency. Participation. Access to information. Ombudsman. 


\section{INTRODUÇÃO}

A concepção da presente pesquisa teve como elementos instigadores alguns instrumentos contemporâneos, advindos com a promulgação da Constituição Federal de 1988. Tais mecanismos, como a Lei de Acesso à Informação - LAl e as Ouvidorias, podem ser analisados a partir de princípios basilares, que norteiam a legitimação do poder, a participação, a fiscalização e o controle, considerando o agir comunicativo, possibilitando maior transparência com a publicação de atos do poder público, ocasionando, consequentemente, maior permeabilidade dos cidadãos nos processos de gestão governamental.

Assim, procurou-se investigar, no cenário político contemporâneo brasileiro, a disponibilidade de mecanismos que possibilitem aos cidadãos - para além das eleições - o acompanhamento, a fiscalização e o controle das ações dos seus representantes. Nesse sentido, o problema central da pesquisa pôde ser expressado com a seguinte indagação: em um cenário com oportunidades tecnológicas, de um lado, e políticas, de outro, quais os efeitos obtidos e os resultados alcançados a partir da institucionalização das Ouvidorias e da LAI como mecanismos de estímulo à participação, fiscalização e controle dos atos dos agentes públicos?

Desde 1985, a partir da redemocratização, a sociedade brasileira tem se organizado, identificando seus direitos e questionando práticas que eventualmente deixem de atender aos interesses sociais e coletivos. Sob a ótica das autoridades, muitas vezes, a população brasileira é caracterizada como contribuinte, pagadora de impostos, mantenedora das máquinas estatais ou, simplesmente, como partícipe temporária do processo, apenas nos períodos eleitorais.

A partir da Constituição Federal de 1988 e, de forma gradual, com o Código de Defesa do Consumidor (Lei n 8.078/1990), a criação da Controladoria-Geral da União (Lei n 10.683/03), a criação da Ouvidoria-Geral da União (Lei n 10.689/2004), a promulgação da Emenda Constitucional $n^{\circ}$ 45/2004 (que determina a criação de Ouvidorias também no Poder Judiciário e no Ministério Público), a Lei de Acesso à Informação - LAI (Lei n 12.527/2011) e o Código de Proteção dos Usuários dos Serviços Públicos (Lei n 13.460/2017), o cidadão passou a dispor de mecanismos de empoderamento político que, aliados às tecnologias da informação e comunicação, possibilitam uma nova dimensão no relacionamento com as instituições governamentais.

Considerando o reconhecimento do aspecto da cidadania, em que "cidadãos" não são apenas eleitores ou destinatários dos serviços públicos, mas devem, de forma contínua, participar ativamente dos processos de monitoramento, fiscalização e controle dos atos praticados pelos agentes do poder público, é fatual e notório um crescente interesse pela institucionalização de meios que possibilitam a aproximação entre governantes e governados.

Atualmente, mais de mil Ouvidores atuam em todo o Brasil. Eles estão na iniciativa privada (área financeira e de seguros, concessionárias de serviços: rodovias, metrô, energia elétrica, telefonia, portos, aeroportos) e na Administração Pública, seja na União, nos Estados, no Distrito Federal e nos Municípios, seja nos poderes Executivo, Legislativo e Judiciário, além do Ministério Público.

Nesse contexto, a Ouvidoria foi sendo implantada dentro das instituições, fazendo parte da estrutura organizacional. Isso tanto nas organizações públicas como nas privadas, mostrando-se dinâmica e aliada na escuta e na apresentação de soluções das mais variadas demandas. 
Se, por um lado, as Ouvidorias vêm dando passos largos como canais inovadores na busca de soluções e na mediação de conflitos e se disponibilizando como meio para a participação do cidadão no acompanhamento e fiscalização dos atos praticados pelas autoridades, por outro há desafios relacionados mais às questões culturais e comportamentais dos atores envolvidos nesse processo, a saber: a) a cultura de pouco se privilegiar a opinião pública; b) a aceitação da opinião pública como indicador para a melhoria dos processos e gestão; c) a fragilidade da cidadania ativa, refletida no reduzido protagonismo e o baixíssimo capital social no Brasil.

É justamente nesse complexo contexto político outrora baseado na cultura do sigilo, do segredo e de limitadas participações sociais e coletivas, e agora com movimentações que sinalizam avanços e boas perspectivas, sob a ótica das Ouvidorias e da Lei de Acesso à Informação, associadas às novas tecnologias da informação e comunicação, que se desenvolveu o presente estudo. $O$ desafio da análise é a interpretação das motivações, dos desdobramentos, as causas e as consequências para a cidadania e a democracia no Brasil.

Dentre os objetivos propostos para a pesquisa, buscou-se analisar o papel das Ouvidorias e da Lei de Acesso à Informação. Tomou-se como intuito demonstrar seus alcances e limitações como mecanismos de accountability, na promoção da transparência, promovendo a cidadania e a democracia a partir da fiscalização, do controle e da participação.

Para lograr êxito na referida análise, procurou-se constituir três pilares como objetivos específicos:

a) identificar, analisar e relacionar os conceitos de accountability, transparência, publicidade e participação política;

b) descrever o movimento das Ouvidorias, desde o cenário internacional até o modelo vigente no Brasil;

c) analisar dados coletados em bases oficiais, demonstrando os impactos, os alcances e as limitações dos mecanismos Ouvidoria e Lei de Acesso à Informação, na promoção da transparência, da publicidade, da fiscalização e do controle sobre o Estado e seus agentes.

\section{DEMOCRACIA, CIDADANIA E PARTICIPAÇÃO: AVANÇOS E PERSPECTIVAS A PARTIR DA REDEMOCRATIZAÇÃO BRASILEIRA}

\subsection{Percurso Metodológico da Pesquisa: entre as Sustentações Teóricas e a Em- piria Orgânica}

Para o alcance dos objetivos propostos na pesquisa, a metodologia utilizada contemplou, no primeiro momento, uma análise bibliográfica. A escolha desse método justificou-se pela densidade dos materiais de referência, como é o caso dos livros e dos artigos científicos, disponíveis e publicados em forma impressa ou virtual, sobre o tema em questão e suas áreas correlatas, possibilitando verificações sobre possíveis atualizações das teorias existentes, valendo-se do aprofundamento teórico, sem perder o foco do objetivo principal, conforme sugere OLIVEIRA (2002). 
Também, por ser tema recente no cenário político contemporâneo em fase de regulamentação e por estar intrinsecamente relacionado aos mais variados instrumentos jurídicos - tais como relatórios, leis, decretos, portarias e instruções normativas -, procurou-se contemplar, ainda, a pesquisa documental, que possui natureza diferenciada das fontes, em relação à bibliográfica, pois vale-se de materiais que ainda não receberam tratamento analítico ou que ainda podem ser reelaborados de acordo com os objetos da pesquisa, devendo ser considerados ainda arquivos processados, mas que podem receber outra interpretação, como é o caso de tabelas, quadros e gráficos (GIL, 2008).

Optou-se por conferir à pesquisa, também, um caráter exploratório, que propiciou aos pesquisadores, após análise bibliográfica e documental, maior familiaridade com o tema, possibilitando explicá-lo com mais fundamentação. A pesquisa exploratória é muito utilizada em caráter preliminar, possibilitando larga compreensão e precisão de fatos recentes e aproximação com o tema, que pode ser construído com base em hipóteses e intuições. Na pesquisa exploratória buscou-se uma análise de como os objetos e as variáveis estudadas se juntam e interagem, além da compreensão de suas causas e efeitos.

\subsection{Accountability, Transparência, Publicidade e Participação Política: Avanços, Limitações e Possibilidades}

Nesta sessão, busca-se a análise de alguns dos principais conceitos na área política, tais como accountability, publicidade e participação. Outro ponto é a verificação das suas inter-relações e contribuições para o fortalecimento da representação política no Brasil.

Inicialmente, sem desmerecer outros instrumentos que muito contribuem para a consolidação da democracia, como é o caso da eleição, parte-se do princípio de que, após os anos 1980, o cenário político brasileiro passou por transformações, deixando de ser a democracia uma ideia subjacente para se tornar um ideal organizador da representação. Assim se enfatiza, para este estudo específico, a criação e o fortalecimento de canais que possibilitem a interação entre Estado e Sociedade, ultrapassando a informalidade, tendo como base arranjos formais e institucionalizados.

Diante desse propósito, em que há um deslocamento de campo da representação política, até então baseada na esfera eleitoral, verificam-se práticas participativas e representativas que vão desde as mais tradicionais, como é o caso do plebiscito e do referendo, passando pelas conferências de políticas públicas, audiências públicas e conselhos, até outras menos tradicionais e conhecidas, como é o caso das Ouvidorias e mesas de negociação e diálogo (ALMEIDA, 2014).

Ainda para além das eleições, que limitam a representação ao sinônimo de democracia eleitoral, ampliar a comunicação entre governantes e governados significa, também, possibilitar mais acesso às variadas fontes de informação, garantindo a prestação de contas e fortalecendo a representação política. Como bem destaca FILGUEIRAS (2011, p. 71), accountability, bem mais do que um processo contábil de prestação de contas, é também "[...] um processo político e democrático, de exercício da autoridade por parte dos cidadãos [...]".

O autor frisa que esse processo sempre depende da interação entre controles horizontais e verticais, mantida a tarefa das instituições políticas de construir mecanismos de prestação de con- 
tas à sociedade, permitindo o controle dos governados sobre o Estado e seus agentes, delimitando fronteiras entre o público e o privado, tornando a gestão do Estado mais permeável à participação da sociedade (FILGUEIRAS, 2011).

A sociedade civil pode empoderar os mecanismos horizontais de controle, exercendo pressão e tornando públicos os abusos de poder. A existência de mecanismos internos de accountability horizontal nas organizações, como instâncias intermediárias de participação, fortalece os meios já existentes para o controle dos líderes.

Observa-se, nesse sentido, que a saída para a democratização da representação não encontra solução na exclusão dos atores que exercem a representação discursiva, mas o aperfeiçoamento dos meios de justificação pública e de diálogo com os indivíduos e grupos representados. Na oportuna análise de ALMEIDA (2014, p. 105 e 106),

[...] A representação política é um processo criativo, no qual o constituinte nunca está dado, como pressupõe o momento eleitoral, mas é construído politicamente. [...] Essa construção não pode ser arbitrária no sentido de desrespeitar tendências do tecido social.

Uma demanda representativa não tem sentido se não for ouvida, vista ou decifrada por seu público-alvo, por aqueles a quem se destina a atrair e convencer. [...] a atenção ao relacionamento entre representantes e representados é essencial para a legitimação democrática desse processo. (Destaque ausente no original.)

Ainda com reflexão em accountability, LAVALLE e ISUNZA VERA (2010 apud ALMEIDA, 2014) destacam outros dispositivos de prestação de contas, denominados de: a) "societal pró-horizontal" ou "pró-vertical" (em que a mobilização da sociedade civil vai ao encontro das agências horizontais de controle em busca da responsabilização dos atores estatais); b) "transversal cidadã" (quando o cidadão atua dentro do aparelho de Estado); e c) "cidadã pró-horizontal” (em que o cidadão ativa a agência de controle horizontal mediante queixas).

LUCHMANN (2012 apud ALMEIDA, 2014) propõe uma reflexão sobre as instituições participativas de uma forma mais dinâmica, com olhar voltado para o impacto nas estruturas governamentais, bem como para as relações com o ambiente social. Um ponto a ressaltar na abordagem em tela é o controle institucional sobre os governos e nas relações com a sociedade.

Mesmo com as mais variadas dificuldades - ocasionadas pelos níveis de dependência entre os atores, tais como a vontade política, a tramitação nos órgãos governamentais e a implementação nos mais diversos contextos sociais -, as instituições participativas servem, de um lado, de ferramenta para a sociedade civil na tentativa de induzir o governo ao atendimento das suas demandas. Os governos e seus agentes, por sua vez, usam as instituições participativas para o atendimento das demandas individuais e coletivas e, ao mesmo tempo, para analisar suas habilidades de mobilização.

Com olhar sobre os mecanismos que podem auxiliar na legitimação do processo representativo, destaca-se amplamente a necessidade de os representantes da sociedade civil estabelecerem um movimento constante de informação, poder e representação. Dessa forma, visando estreitar os laços de participação diretamente com a população, é necessário o desenvolvimento de canais permanentes de transparência e de interação. 
Nesse sentido, STIGLITZ (1999 apud FILGUEIRAS, 2011, p. 72) destaca que a transparência não deve ser tão somente a abertura de dados, mas "[...] a redução das assimetrias informacionais entre cidadãos e agentes estatais, de maneira a reduzir as falhas de gestão e permitir maior controle sobre os atos ilícitos cometidos no setor público [...]".

Para ROUMEEM ISLAM (2003 apud FILGUEIRAS, 2011, p. 73) "[...] governos transparentes governam melhor porque a ampliação da informação proporciona a existência de um mercado político com menos corrupção e, por sua vez, mais eficiência". Assim, a accountability é aprimorada com a ampliação da transparência, que, por sua vez, garante um sistema de responsabilização a partir da abertura dos segredos de Estado. A transparência, ao passo que reduz os segredos de Estado, amplia o exercício da cidadania, enquanto a cultura do segredo, de forma inversa, fragiliza a democracia.

Por outro lado, deve-se considerar que um Estado transparente não significa, necessariamente, a presença de um julgamento imparcial no âmbito da sociedade, pois sem a imparcialidade na deliberação a política de transparência nutre o escândalo, em que mais importa a vida privada, a intimidade e a reputação dos indivíduos do que as questões públicas propriamente ditas. Isso pode trazer à tona algumas divergências, como aquela entre a liberdade de expressão e a liberdade individual.

À transparência deve-se acrescentar outro viés, que diz respeito ao sigilo das informações estratégicas. Conforme THOMPSON (1999 apud Filgueiras, 2011, p. 81), certas políticas requerem segredo, devido à sua natureza, tais como "[...] as investigações policiais, o combate ao tráfico de drogas e decisões econômicas sobre juros e política financeira [...]".

Nesse sentido, nem sempre a abertura completa das informações e a transparência vão significar maior eficiência das políticas públicas. Ainda nesse contexto, disponibilizar mais informações não significa, necessariamente, produzir cidadãos melhores, mais atuantes e vigilantes em relação aos atos públicos.

A Ouvidoria-Geral da União - OGU disponibiliza, para acompanhamento por qualquer pessoa, os relatórios estatísticos sobre pedidos e recursos realizados no âmbito da Lei de Acesso à Informação - LAI, com base em dados extraídos, diariamente, do e-SIC (Sistema de Informação ao Cidadão). Tais relatórios permitem que o cidadão monitore a implementação da Lei de Acesso à Informação e verifique o desempenho dos órgãos e entidades, a partir de dados consolidados de todo o Poder Executivo Federal ou dados específicos de um órgão/entidade cadastrado no e-SIC.

No Gráfico 1, logo a seguir, são apresentados números relativos às negativas de acesso à informação, referentes ao período entre maio/2012 e dezembro/2017, com os principais motivos para a não concessão de acesso. Os resultados do referido gráfico vão ao encontro das proposições feitas por FILGUEIRAS (2011), uma vez que, dos 48.782 (100\%) acessos negados aos usuários que invocaram, na ocasião, a Lei de Acesso à Informação, 15.300 pedidos (ou seja, $31,3 \%$ do total) indicavam maior interesse dos usuários na vida privada, na reputação e na intimidade de um agente público do que em um ato institucional, na instituição ou na coisa pública propriamente dita. 
Nesse mesmo sentido, 11.369 pedidos (ou $23,2 \%$ do total) foram negados, uma vez que as informações requeridas são protegidas por legislação específica, podendo conter conteúdo estratégico, relativo a segurança ou economia, por exemplo.

\section{GRÁFICO 1 - Razões Negativas de Acesso - Lei de Acesso à Informação - LAl (período: 05/2012 a 12/2017)}

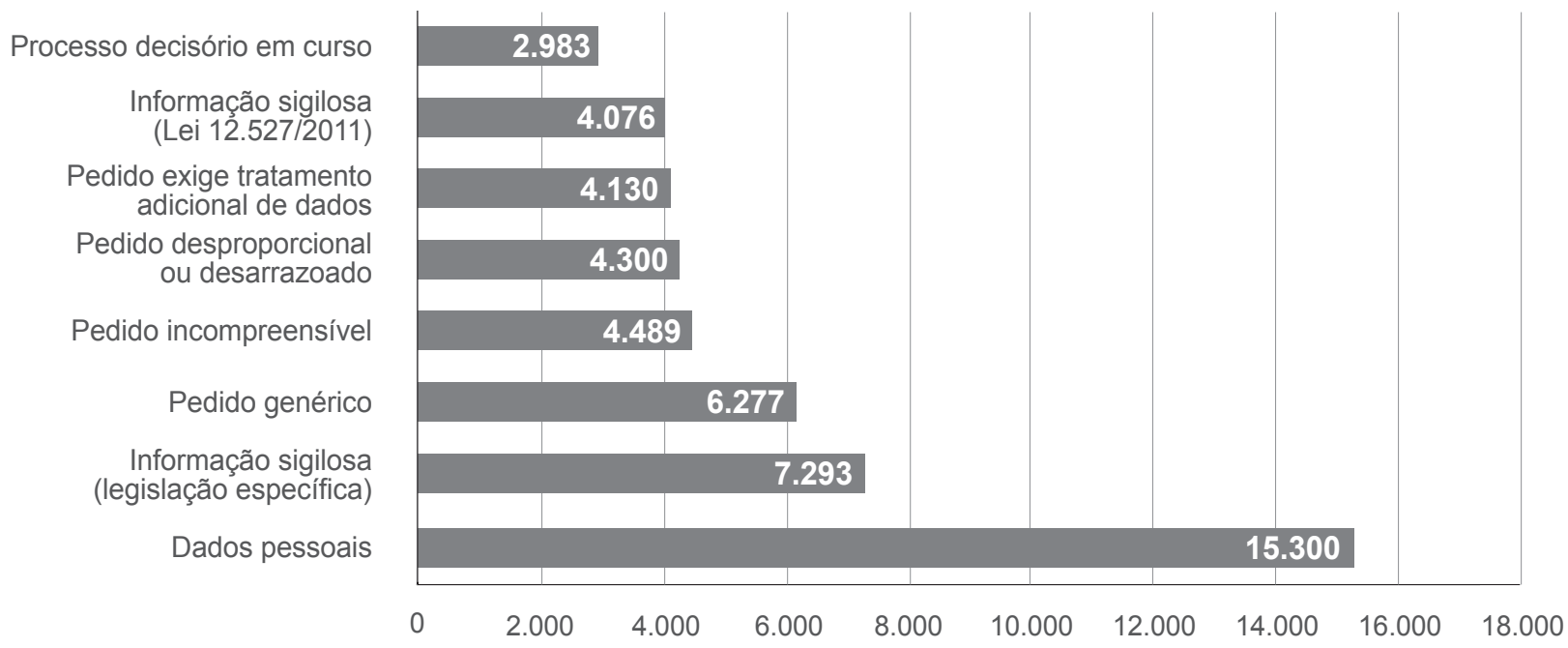

Fonte: elaboração própria dos autores, a partir de base de dados da Controladoria-Geral da União - CGU, disponível em: https://esic.cgu.gov.br/sistema/Relatorios/Anual/RelatorioAnualPedidos.aspx

A transparência, quando vinculada à publicidade, deve possibilitar que a accountability cumpra seu princípio de legitimação em regimes políticos democráticos, reiterando seu papel no conjunto de processos, procedimentos e valores atrelados ao ideal de responsabilização e de controle dos governos.

Se a transparência se refere à disponibilização de informações e processos relacionados às políticas públicas, a publicidade vai além, por ser um princípio de autoridade, devendo não ficar restrita ao sistema hegemônico da comunicação na sociedade, mas garantindo a reciprocidade do discurso dos interessados nas políticas e decisões do governo.

Dessa forma, no entendimento de CHRISTIANO (2004 apud FILGUEIRAS, 2011, p. 84), a publicidade "[...] exige que os processos representativos da democracia sejam organizados em condições equitativas [...]". FILGUEIRAS (2011, p. 90) complementa tal reflexão destacando que:

[...] a accountability dos sistemas políticos exige um compromisso republicano com concepções de boa vida e bom governo [...]. Ela requer uma concepção politicamente 
orientada ao público e aos cidadãos completos, que não se eximem de se fazer ouvir, serem ouvidos e ouvirem os outros [...] (Destaque ausente no original.)

\subsection{As Ouvidorias e a Lei de Acesso à Informação na Promoção da Participação Política: Conexões, Rupturas e Desafios}

Após a redemocratização do Brasil, com a promulgação da Constituição Federal de 1988, que assegurou em seu texto direitos e liberdades até então restritos a parcelas de indivíduos, observou-se, aos poucos, a construção de uma nova relação entre o poder público e a sociedade. Assim, observa-se que, a priori, os cidadãos buscam, cada vez mais, meios de participar das decisões que envolvem os interesses coletivos, seja pela cobrança por mais transparência e eficiência na Administração Pública, ou pela participação direta, com o uso de dispositivos que possibilitam os registros de críticas, sugestões, propostas, como é o caso das Ouvidorias, ou monitoramento constante das ações dos agentes públicos, por meio da Lei de Acesso à Informação.

Tais transformações permeiam, necessariamente, o aumento do interesse na busca por mais informações a respeito da gestão da coisa pública. E isso, com obviedade, exige dos governos, cada vez mais, abertura, transparência e uma postura horizontalizada com os cidadãos.

Se de um lado observa-se a emergência de mecanismos que estimulam e asseguram o controle e a participação, por outro há uma inquietação causada, principalmente, pelos recorrentes casos de clientelismo, contaminando as práticas políticas nas democracias modernas. Esse fato se deve, em grande parte, à concentração do poder nos mais variados aparatos do Estado, ocasionando, conforme destacam DIAMOND e MORLINO (apud Formiga XAVIER, 2011), a perda da confiança pública nas instituições governamentais e políticas, associada à percepção generalizada de que os governos democráticos e políticos são cada vez mais corruptos e que atuam na defesa de interesses particulares.

É incontestável que há uma crise de confiança crescente nas instituições e regimes democráticos, especialmente nos regimes democráticos mais recentes. Diante desse cenário, são necessários e indispensáveis os novos instrumentos de controle das ações da Administração Pública e dos seus agentes, pois, conforme FILGUEIRAS (2008-b, p. 160), "[...] caso não haja a construção de mecanismos de responsabilização dos políticos na institucionalidade democrática, o risco de crescente deslegitimação é grande".

Deve-se destacar aqui que historicamente as eleições são reconhecidas como mecanismos de escolha dos representantes de uma sociedade, tendo sido consolidadas como instrumentos de uma democracia representativa bem-sucedida. No entanto, e como já destacado anteriormente, as eleições, por si só, não se configuram como suficientes e garantidoras da democracia em sua plenitude, pois esta necessita, além do procedimento eleitoral, de mecanismos permanentes e constantes para o controle dos atos dos agentes públicos e da máquina estatal.

A partir da década de 1970, a teoria da democracia passou a contar com a proposição de argumentos de autores que defendiam a ampla participação da cidadania nos processos políticos, 
para além das eleições. No cenário brasileiro, a partir da Constituição Federal de 1988, surgiram movimentos em prol dos orçamentos participativos, das audiências públicas, dos referendos, dos plebiscitos, além de outros mecanismos que possibilitam uma maior intervenção e monitoramento da cidadania na esfera pública.

De acordo com WEISSBERG (2003 apud MARQUES, 2016), uma análise do cenário político contemporâneo deve levar em consideração, principalmente, o capital social ou o engajamento e ativismo do cidadão nas ações cotidianas dos agentes públicos e como se dá a relação entre esses atores e os mecanismos disponíveis de interação, com ênfase para as novas tecnologias de informação e comunicação.

Partindo-se do princípio de que a democracia requer a soberania popular e esta, por sua vez, não se fundamenta somente na participação do cidadão em variadas instâncias, deve-se compreender o nível em que se asseguram os direitos individuais e as oportunidades para que a esfera cidadã permeie na esfera do Estado e atue de forma a fiscalizar e questionar os atos governamentais.

Nesse sentido, justifica-se uma análise aprofundada sobre a representação contínua e a capacidade de acompanhamento e avaliação do desempenho das instituições estatais e dos representantes, sob a égide do princípio da transparência e, indissociavelmente, a prestação de contas sobre os atos praticados na Administração Pública, evitando a corrupção e ampliando a confiança e o capital social. De acordo com MARQUES (2016, p. 22),

[...] No fim das contas, o objetivo de autores que defendem uma versão mais sofisticada de transparência é fazer não apenas com que a esfera civil mantenha um domínio diligente sobre o conjunto de informações públicas, mas que, em um momento posterior, pressione o Estado a criar modos de escutar o cidadão. (Destaque ausente no original.)

As novas tecnologias de informação e comunicação possibilitam a ampliação da participação cidadã sobre a fiscalização e o controle das atividades dos representantes e da Administração Pública por diversos motivos, dos quais dois podem ser destacados: a) a agilidade na divulgação; b) a facilidade de acesso. Exemplo disso é a regulamentação de dispositivo constitucional por meio da Lei de Acesso à Informação que possibilita o acesso às informações públicas, colaborando para um ambiente fértil à promoção da transparência, fiscalização e controle.

O Portal da Transparência do Governo Federal Brasileiro, mantido pelo Ministério da Transparência, Fiscalização e Controladoria-Geral da União - CGU, é uma ferramenta que permite a todo cidadão fiscalizar, em tempo real, a aplicação do dinheiro público, com a disponibilização de dados relativos às despesas efetuadas pelas instituições do Estado.

O Gráfico 2, apresentado a seguir, mostra em números expressivos a quantidade crescente de acessos ao Portal da Transparência, entre os anos de 2004 e 2017. Observa-se, de modo geral, entre os anos de 2004 e 2017 (intervalo de 12 anos), um grande crescimento no número de acessos ao portal. O gráfico ressalta, ainda, uma elevação mais vertiginosa no número de acessos no período entre os anos de 2012 e 2016 (intervalo de 5 anos), que se pode justificar 
por ser esse período coincidente com o da publicação da Lei de Acesso à Informação que, por sua vez, passou a vigorar no ano de 2012.

\section{GRÁFICO 2 - Total de acessos ao Portal da Transparência do Governo Federal (Período: 2004 a 2017)}

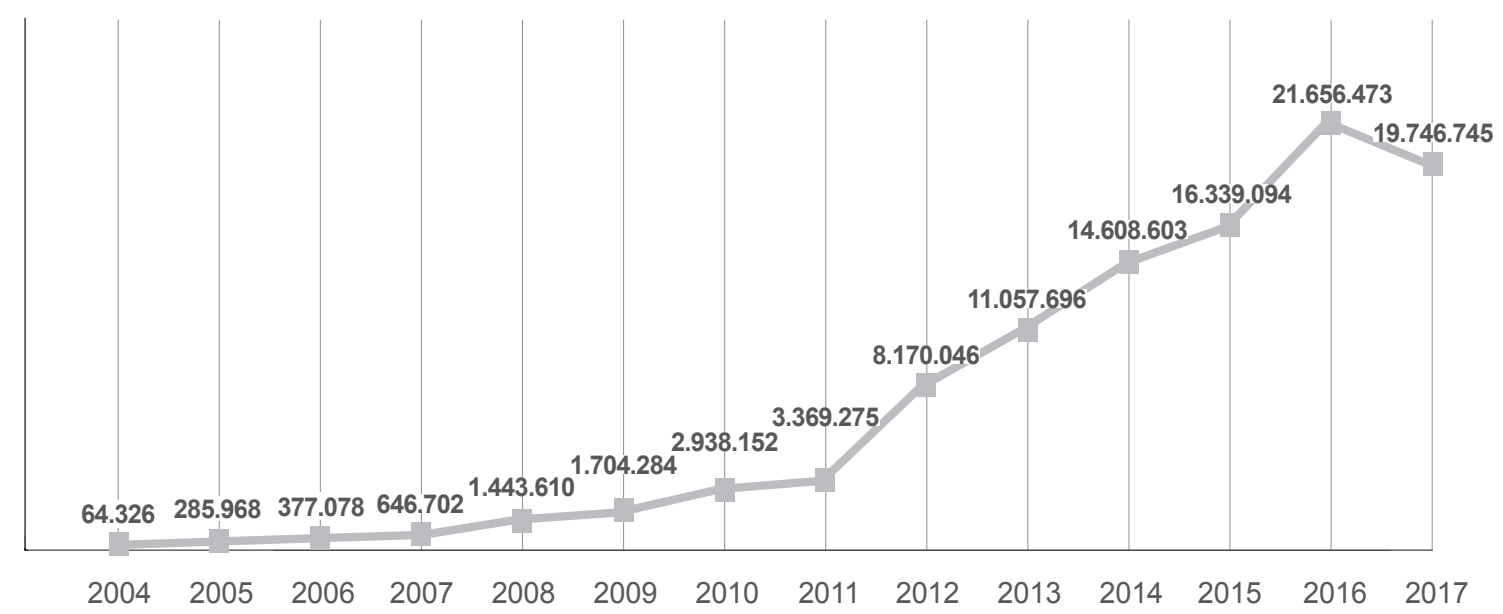

Fonte: elaboração própria dos autores, a partir de base de dados do Ministério da Transparência, Fiscalização e Controladoria-Geral da União (CGU). Disponível em: http://www.portaldatransparencia.gov.br/sobre.

Por outro lado, e muito além do acesso às informações, existe a Ouvidoria. Ela se configura como mecanismo que possibilita ao cidadão o registro de suas demandas (informações, sugestões, denúncias, reclamações ou elogios), integrando em sua natureza e em seus princípios a verificação e análise de cada registro recebido, a confirmação da sua veracidade e a adoção de medidas para posterior resposta ao demandante.

Deve-se salientar que o tema Ouvidoria ainda esteve presente na agenda pública do Brasil na passagem do período ditatorial para a (re)democratização, ganhando relevância nas discussões constituintes e na redação do texto da Carta Magna de 1988. Destaca-se, nesse contexto, a proposta de criação da Defensoria do Povo, pela Comissão Provisória de Estudos Constitucionais, presidida por Afonso Arinos.

O Defensor do Povo seria alguém escolhido a partir de nomes indicados pela sociedade civil, conforme ocorria na Constituição Espanhola de 1978. A redação do Anteprojeto da Comissão de Estudos Constitucionais (BRASIL, 1986) considerava:

[...] Art. 56 - É criado o Defensor do Povo, incumbido, na forma da lei complementar, de zelar pelo efetivo respeito dos poderes do Estado aos direitos assegurados nesta Constituição, apurando abusos e omissões de qualquer autoridade e indicando aos órgãos competentes as medidas necessárias à sua correção ou punição [...]. 
No entanto, a referida proposta de um Defensor do Povo não foi levada ao plenário para inclusão no texto constitucional. Em seu lugar, optou-se pela delegação de parte de suas funções ao Ministério Público.

Contudo, ao tratar da Administração Pública, os constituintes garantiram um dispositivo que possibilitasse o controle da prestação dos serviços aos cidadãos por meio de uma lei ordinária, conforme Emenda Constitucional n 19, de 1998. Na Constituição Federal de 1988 (BRASIL, 1988), tem-se a seguinte redação:

\section{[...] Art. 37}

$\S 3^{\circ}$ A lei disciplinará as formas de participação do usuário na Administração Pública direta e indireta, regulando especialmente:

I - as reclamações relativas à prestação dos serviços públicos em geral, asseguradas a manutenção de serviços de atendimento ao usuário e a avaliação periódica, externa e interna, da qualidade dos serviços;

II - o acesso dos usuários a registros administrativos e a informações sobre atos de governo, observado o disposto no art. $5^{\circ}, \mathrm{X}$ e XXXIII. (Destaque ausente no original.)

Se o dispositivo legal supramencionado frustrou as expectativas daqueles que acreditavam na criação de uma Ouvidoria para atuação em âmbito nacional, com respaldo constitucional, observou-se a continuidade da inquietude na sociedade nos anos seguintes, buscando maior participação do cidadão por meio dos mecanismos de controle sobre as ações da Administração Pública. Assim, o art. 37 da Constituição Federal de 1988 acabou promovendo a implantação de Ouvidorias setoriais nas mais diversas unidades do poder público, nos níveis federal, estadual e municipal.

Ainda que o objeto do presente estudo seja, essencialmente, a transparência e o controle das atividades da Administração Pública pelos cidadãos, faz-se jus registrar a criação do primeiro Ombudsman, no ano de 1989, no jornal Folha de São Paulo, tendo como elemento motivador o Código de Defesa do Consumidor - CDC, instituído pela Lei nº 8.078 de 1990.

Também, deve-se registrar que, imediatamente após o início da vigência do Código de Defesa do Consumidor, viu-se a adoção de prática semelhante em outras empresas privadas. Além disso, houve a oportunidade da fundação, em 1995, da Associação Brasileira de Ouvidores - ABO, que cumpre relevante papel nos processos de disseminação e fortalecimento do instituto das Ouvidorias no Brasil. Um ano mais tarde, em 1996, ocorreu a criação da Ouvidoria-Geral da República, inicialmente instalada nas estruturas do Ministério da Justiça, conforme Decretos $n^{\circ}$ 1.796/1996 e $n^{\circ}$ 2.802/1998 (BRASIL, 2012).

No ano de 2003, a Ouvidoria-Geral da República ganha mais autonomia, sendo transferida para a Controladoria-Geral da União - CGU e, posteriormente, tem sua nomenclatura alterada para Ouvidoria-Geral da União - OGU, vigorando até a presente data, com competência para exercer a coordenação técnica do segmento das Ouvidorias dos diversos órgãos do Poder Executivo Federal.

Em 2004, houve a promulgação da Emenda Constitucional $n^{\circ} 45$, determinando a criação de Ouvidorias no Poder Judiciário e no Ministério Público, no âmbito da União, dos Estados, do Distrito Federal e nos Territórios. 
Esse processo de ampliação dos espaços de participação fez com que a Ouvidoria estivesse presente nos poderes executivo, legislativo e judiciário, em âmbito federal, e também nos estados, no Distrito Federal e nos municípios. Assim, consolidou-se a Ouvidoria como instância de controle e participação social, destinada ao aprimoramento da gestão pública.

No Gráfico 3, apresentado a seguir, é possível constatar um crescimento no número de Ouvidorias, entre os anos de 2002 e 2014, no âmbito dos órgãos do Poder Executivo Federal. De acordo com análise constante no Relatório de Pesquisa da Controladoria-Geral da União - CGU/Instituto de Pesquisa Econômica Aplicada - IPEA, "[...] Ao final de 2012, o Ouvidor-Geral da União, José Eduardo Elias Romão, estimava em dois mil o número de Ouvidorias Públicas no Brasil, sendo mais de $90 \%$ desse total representado pelas Ouvidorias estaduais e municipais [...]" (COLETA OGU, 2014, p. 5).

O crescimento de $712,5 \%$ entre os anos de 2002 e 2014 evidenciado no referido gráfico, para além do atendimento da legislação que determina e orienta a criação e o funcionamento das Ouvidorias na esfera pública, é também um indicador de que as Ouvidorias - afora os mecanismos de fiscalização, controle e participação - auxiliam nos processos de gestão ao tratar seus registros como indicadores que possibilitam avaliar a prestação dos serviços pelo poder público, de um lado, e o nível de satisfação dos cidadãos, de outro.

\section{GRÁFICO 3 - Evolução do Número de Ouvidorias do Poder Executivo Federal (período: 2002 - 2014)}

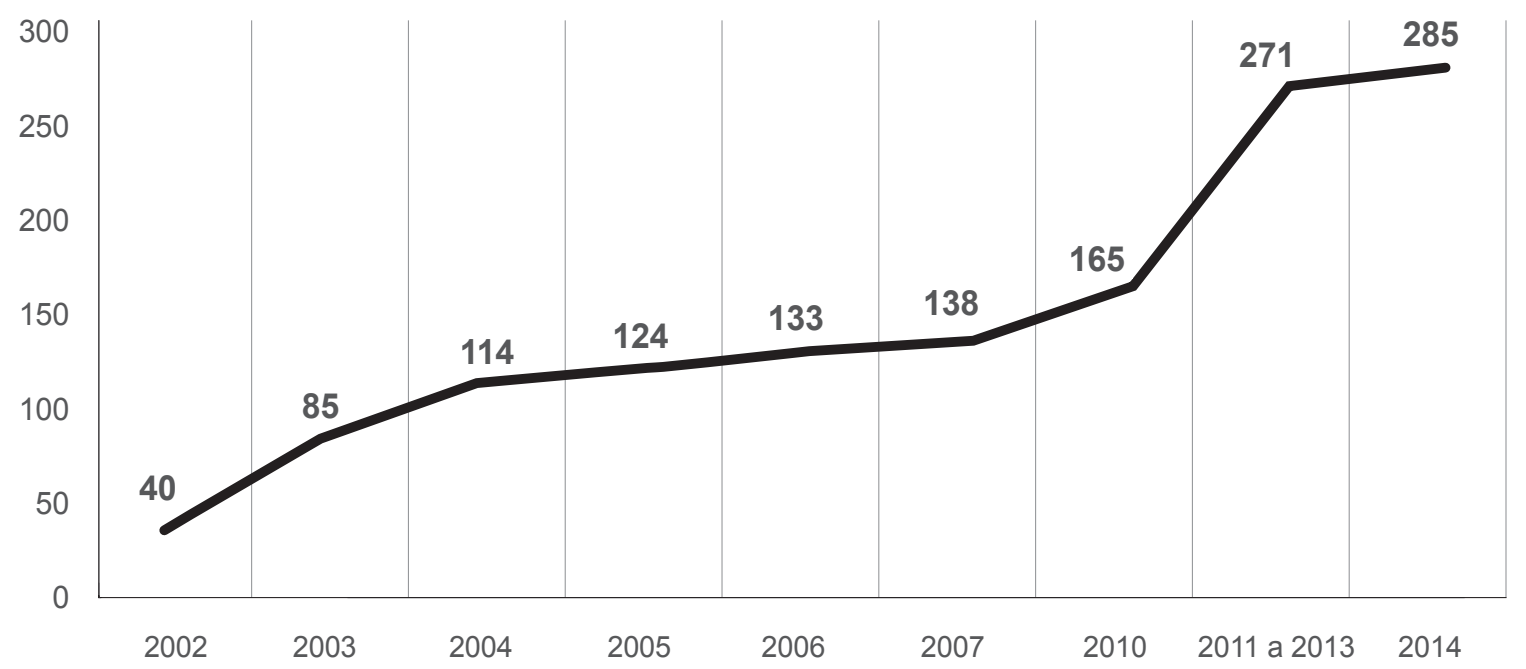

Fonte: Coleta OGU 2014: Relatório de Pesquisa (Instituto de Pesquisa Econômica Aplicada - IPEA/Controladoria-Geral da União - CGU/Ouvidoria-Geral da União - OGU). Disponível em: http://www.cgu.gov.br/Publicacoes/Ouvidoria/coleta-ogu.

As Ouvidorias são espaços da esfera pública que permitem a participação dos cidadãos na discussão sobre a prestação de serviços, o atendimento de normas, a resolução de conflitos, além 
de outras atribuições, formando estrutura social baseada em uma noção de cidadania participativa, tornando mais permeáveis os canais de acesso ao poder (MARQUES; CARVALHO, 2017).

Complementando essa interpretação, BERTACHINI (2014, p. 06) salienta que:

[...] Na realidade brasileira, independentemente de ser chamado de Ouvidor ou Ombudsman, não há diferenças quanto à proposição de medidas correcionais e preventivas, pois ambos antecipam tendências para melhorias dos serviços e participam de projetos de planejamento estratégico na Organização [...]. (Destaque ausente no original.)

\section{CONSIDERAÇÕES FINAIS}

As análises relativas à transparência e à publicidade permitiram encontrar subsídios para refletir sobre a participação ativa do cidadão nos processos de fiscalização e controle sobre as instituições e agentes do Estado. Assim, os resultados das análises confirmam, de um lado, que a abertura de dados e o acesso à informação mostram-se crescentes em uma escala temporal progressiva.

No entanto, em contrapartida, de acordo com o que os números mostraram, é também notório o elevado interesse na vida privada e na intimidade dos agentes públicos, em detrimento da importância nas instituições e suas dinâmicas. E isso torna mais tênues as fronteiras entre o público e o privado.

Para além das divergências conceituais e suas limitações em relação ao que se deseja alcançar - seja a transparência, a publicidade ou a ação do cidadão sobre o conhecimento obtido -, foi possível constatar e reafirmar o anseio por mecanismos que possibilitem, cada vez mais, a atuação cidadã, de forma mais inclusiva e constante, complementando as limitações percebidas em mecanismos já tradicionais, como é o caso das eleições.

Nesse sentido, verifica-se que tanto as Ouvidorias como a Lei de Acesso à Informação constituem engrenagens contemporâneas que vêm possibilitando resgatar os ideais constituintes, expressados na Constituição Federal de 1988, lançando luz sobre a importância da accountability, sem dissociá-la da transparência, da publicidade, do controle, da fiscalização e da participação.

Ao analisar o cenário atual, pode-se observar também que, mesmo com algumas diferenças em suas formas de atuação, ocasionadas principalmente pela natureza jurídica das suas instituições, as Ouvidorias brasileiras preservam o princípio maior do instituto sueco do Ombudsman, que é a promoção da participação cidadã e o fortalecimento da democracia.

\section{REFERÊNCIAS}

ALMEIDA, Débora Rezende de. Pluralização da representação política e legitimidade democrática: lições das instituições participativas no Brasil. Opinião Pública, Campinas, v. 20. n. 01, p. 96-117, abr. 2014. 
BRASIL. Lei 13.460, de 26 de junho de 2017 (Dispõe sobre participação, proteção e defesa dos direitos do usuário dos serviços públicos da Administração Pública). Disponível em: <http://www2.camara.leg.br/legin/fed/lei/2017/lei-1346026-junho-2017-785098-norma-pl.html>. Acesso em: 10 out. 2017.

Código de Proteção e Defesa do Consumidor (1990). Código de proteção e defesa do consumidor e legislação correlata, 5. ed., Brasília: Senado Federal, Subsecretaria de Edições Técnicas, 2012. 106 p.

Controladoria-Geral da União / Ouvidoria-Geral da União. Orientações para implantação de uma unidade de Ouvidoria: rumo ao sistema participativo. Brasília, 2012. (Coleção OGU. 5. ed. revista e atualizada.) Disponível em: <http://www.Ouvidorias.gov.br/central-de-conteudos/biblioteca/arquivos/cartilhas/cartilha-1.pdf/view>. Acesso em: 10 out. 2017.

Coleta OGU 2014: relatório de pesquisa. Instituto de Pesquisa Econômica Aplicada - IPEA/Controladoria-Geral da União - CGU. Brasília, 2015. Disponível em: <http://www.cgu.gov.br/Publicacoes/Ouvidoria/coleta-ogu>. Acesso em: 02 abr. 2018.

Lei de Acesso à Informação: cartilha de orientação ao cidadão. Brasília: Câmara dos Deputados, Edições Câmara, 2012. 31 p. (Série fontes de referência. Guias e manuais; n. 33). ISBN 978-85-736-5963-4.

Presidência da República. Emenda Constitucional № 45, de 30 de Dezembro de 2004. Disponível em: <

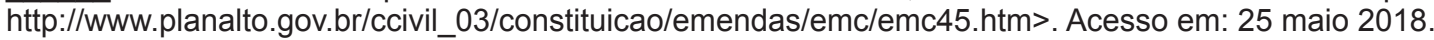

Presidência da República. Lei № 10.869, de 13 de maio de 2004 (Altera a Lei no 10.683, de 28 de maio de 2003, que dispõe sobre a organização da Presidência da República e dos Ministérios, e dá outras providências). Disponível em: < https://www.planalto.gov.br/ccivil_03/_Ato2004-2006/2004/Lei/L10.869.htm>. Acesso em: 25 maio 2018.

Senado Federal. Constituição da República Federativa do Brasil: texto constitucional promulgado em 5 de

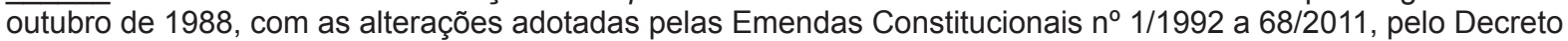
Legislativo $n^{\circ}$ 186/2008 e pelas Emendas Constitucionais de Revisão n 1 a 6/1994, 35. ed., Brasília: Câmara dos Deputados, Edições Câmara, 2012. 454 p. (Série textos básicos; n. 67). ISBN 978-85-736-5934-4.

Senado Federal. Decreto No 93.714, de 15 de Dezembro de 1986. Disponível em: <http://legis.senado.gov.br/ legislacao/ListaPublicacoes.action?id=220747>. Acesso em: 25 out. 2017.

FILGUEIRAS, Fernando. Corrupção, Democracia e Legitimidade. Belo Horizonte: Editora UFMG, 2008-b.

FILGUEIRAS, Fernando. Além da transparência: accountability e política da publicidade. Lua Nova, São Paulo, n. 84. p. 353-364, 2011.

FORMIGA XAVIER, Carlos Joel Carvalho de. A corrupção política e o caixa 2 de campanha no Brasil. Dissertação (mestrado). Faculdade de Filosofia, Letras e Ciências Humanas da Universidade de São Paulo. Departamento de Ciência Política. Área de concentração: ciência política. 2011. Disponível em: <http://www.teses.usp.br/teses/disponiveis/8/.../2010_CarlosJoelCarvalhodeFormigaXavier.pdf>. Acesso em: 14 out. 2017.

GIL, Antônio Carlos. Como elaborar projetos de pesquisa. 4. ed. São Paulo: Atlas, 2008.

MARQUES, Francisco Paulo Jamil. Ciberpolítica: conceitos e experiências. (Coleção Cibercultura). Salvador: EDUFBA, 2016.

MARQUES, Paulo Marcello Fonseca; CARVALHO, Guilherme Paiva de. Legitimação do poder, agir comunicativo e gestão democrática em uma Ouvidoria universitária. In: PODESTÁ JÚNIOR, Arnaldo; PFAFFENSELLER, Ana Cláudia de Almeida; OLIVEIRA, Alan Santos de. Ouvidoria no Brasil e seus desafios: olhares de norte a sul (Relatos de experiências em Instituições de Ensino Superior e Hospitais Universitários). Florianópolis: Tribo da Ilha, 2017.

OLIVEIRA, Silvio Luiz de. Tratado de metodologia científica: projetos de pesquisas, TGI, TCC, monografias, dissertações e teses. São Paulo: Pioneira Thomson Learning, 2002.

QUEIROZ, Roosevelt Brasil. Formação e gestão de políticas públicas (Série: Gestão Pública). Curitiba: InterSaberes, 2012. 